\title{
ROSJA I EUROPA ŚRODKOWA W GEOGRAFII SYMBOLICZNEJ I LITERACKIEJ (UWAGI IMAGOLOGICZNE)
}

\author{
MILOŠ ZELENKA ${ }^{1}$ \\ (Czeskie Budziejowice)
}

\begin{abstract}
Słowa kluczowe: Rosja, Europa Środkowa, geografia literacka, międzykulturowe studia komparatystyczne, imagologia
\end{abstract}

Keywords: Russia, Central Europe, literary geography, intercultural studies, imagology

\begin{abstract}
Abstrakt: Miloš Zelenka, ROSJA I EUROPA ŚRODKOWA W GEOGRAFII SYMBOLICZNEJ I LITERACKIEJ (UWAGI IMAGOLOGICZNE). „PORÓWNANIA” 11, 2012, Vol. XI, s. 31-41, ISSN 1733-165X. Badając, jak wzajemne postrzeganie Europy Środkowej i Rosji zmieniało się na tle złożonych relacji między Wschodem a Zachodem, artykuł czerpie z elementów teorii komunikacji i studiów międzykulturowych (C. Gullién, H. Dyserinck, D. H. Pageaux, D. Ďurišin, etc.) znanych jako imagologia. Jako obszar geograficzny kulturowych przecięć, gdzie weszły ze sobą w kontakt niesłowiański Zachód i słowiański Wschód, Europa Środkowa zawsze wyróżniała się zmienną pozycją przejściowych centrów i peryferii ze specyficzną mieszanką grup etnicznych, kultur, religii i ideologii. Fakt, że leży ona pomiędzy dwoma tak potężnymi narodami, jak Niemcy i Rosja, wywarł fundamentalny wpływ nie tylko na polityczną, ale i estetyczną komunikację pomiędzy narodami słowiańskimi i Zachodem, który często ujmowany był za pomocą mitów, tzn. fikcjonalnych i subiektywnych obrazów służących do interpretowania rzeczywistości. Wzajemne schodzenie się i rozchodzenie Rosji i Zachodu wynikało z różnic religijnych i "rozdarcia” narodów słowiańskich (przede wszystkim Słowian zachodnich), którzy oprócz trzymania się zachodniej religii i reguł politycznych, pielęgnowali niechęć w stosunku do plemiennej wspólnoty z Rosją. Najsilniejsze więzy z Rosją demonstrowały więc małe narody słowiańskie, żyjące w imperium habsburskim, podczas gdy rosyjskie interesy w Europie skierowane były raczej na Niemcy, Francję lub Anglię, a obszar środkowoeuropejski uznano za strefę przejściową, traktowaną przez carską Rosję lub Związek Radziecki jako siłę polityczną do prowadzenia własnej polityki względem Zachodu. W przeciwieństwie do tego stanowiska, narody środkowoeuropejskie, nie wyłączając z nich Czechów, nawiązywały relacje z Rosją jako inspirującym liderem i symbolem słowiańskiej niezależności, szczególnie w czasach kłopotów, zagrożenia narodowego i politycznej niestabilności. Ich oczekiwania opierały się na powszechnym
\end{abstract}

${ }^{1}$ Correspondence Address: zelenka@pf.jcu.cz 
przekonaniu, że „nieeuropejska” Rosja i jej inność zdemokratyzuje się poprzez podążanie drogą lokalnej tradycji i popieranie czeskich interesów w geopolitycznej konfrontacji z niesłowiańskim Zachodem. Jak się wydaje, relacja pomiędzy Europą Środkową i Rosją pozostanie centrum permanentnej refleksji metakrytycznej nawet na początku XXI wieku i pozostaje mieć nadzieję, że będzie to model harmonijnej współegzystencji, wzajemnego zrozumienia i szacunku.

\section{Abstract: Miloš Zelenka, RUSSIA AND CENTRAL EUROPE IN SYMBOLIC AND LITERARY} GEOGRAPHY (IMAGOLOGICAL REMARKS). "PORÓWNANIA“ 11, 2012, Vol. XI, p. 31-41, ISSN 1733-165X. While examining mutual perception of Central Europe and Russia as it has changed against the background of the complex East-West relation, the paper employs the motives of the theory of communication and intercultural studies (C. Guillén, H. Dyserinck, D. H. Pageaux, D. Duurišin, etc.) known as imagology. As a cultural crossroads and geographical area where the non-Slavonic West and the Slavonic East come into contact, Central Europe has always featured a changeable position of transitional centres and peripheries with the specific mingling of ethnics, cultures, religions and ideologies. The fact that it is situated between two powerful nations, such as Germany and Russia, has fundamentally influenced not only political but also aesthetical communication between the Slavonic peoples and the West, which has often been maintained through myths, i.e. fictional and subjective images to interpret the reality. The mutual converging or diverging of Russia and the West has resulted from the religious oscillation and "splitting" of Slavonic peoples (namely the West Slavs) who, despite adhering to Western religion and policies, have fostered awareness of tribal affinity with Russia. The strongest ties with Russia were thus maintained by small Slavonic nations living in the Hapsburg Empire, whereas the Russian interest in Europe was rather aimed at Germany, France or England, and Central European area was deemed to be a zone of transition employed by Tsarist Russia or the Soviet Union as political powers to pursue their goals in the West. In contrast to it, Central European nations, the Czechs not excluding, forged ties with Russia as the inspiring leader and symbol of Slavonic independence, the more so in times of troubles, national danger and political instability. Their expectations were based on the common belief that "non-European" Russia and its otherness would become democratised through following the local tradition and supporting Czech interests in the geopolitical confrontation with the non-Slavonic West. As it seems, the relation between Central Europe and Russia will remain the focus of permanent metacritical discourse even in the early 21st century and one can only cherish hope that it will be a model of harmonious coexistence, mutual understanding and respect.

Badanie wzajemnych związków kulturowych między wspólnotami międzyliterackimi, jak na przykład między Rosją a Europą Środkową, można zaliczyć do podstawowych zadań komparatystycznych eksploracji, które odkrywają „porównywalność" na podstawie odmienności, albo analizują „inność" przy pomocy częściowego podobieństwa². Dla tego typu międzykulturowych studiów komparaty-

${ }^{2}$ M. Zelenka, Interkulturní studia v kontextu soudobé literární historiografie: "komparováni”“ jako způsob interpretace psaní literárních dějin. „World Literature Studies“ 2010, nr 2 (19), z. 4, s. 74-83; dalej zob. 
stycznych obowiązuje zasada, iż literatura porównawcza nie potrzebuje podczas badania wpływów i "kontaktu literackiego" metonimicznego "sąsiedztwa”, czyli bliskości geograficznej. Według hiszpańskiego komparatysty C. Guilléna istnieją trzy typy badań porównawczych zbudowanych na różnych modelach ponadnarodowości ${ }^{3}$. W pierwszym typie ponadnarodowość jest rozumiana jako genetyczny kontakt różnych kultur narodowych. Drugi typ ponadnarodowości związany jest z zależnościami charakteru typologicznego. Trzeci jest realizowany w modelu teoretycznym, który Guillén definiuje jako otwarte zderzenie krytyki i historii $\mathrm{z}$ teorią. $\mathrm{Z}$ badaniami interkulturowymi związana jest także tzw. imagologia jako dyscyplina literatury porównawczej, która za pomocą obrazu (les images) obcego (heteroimages) i własnego (autoimages) bada topos „innego" w tekstach literackich ${ }^{4}$. Obrazy te w większości przypadków nabierają cech stereotypów, mitów, uprzedzeń oraz cliché i są wyrazem dyskursu intelektualnego tworzonego przez rozmaite grupy etniczne i socjalne. Dlatego jednostki i grupy społeczne nie potrafią $\mathrm{w}$ procesie poznawania obiektywnie uchwycić segmentów czy też samej istoty pozatekstowej rzeczywistości, ale za pośrednictwem metapozycji, czyli opisów językowo-syntaktycznych tworzą ideologiczną konstrukcję świata. W inspirujących badaniach "narodowych” mitów lub iluzji przy pomocy artystycznych (fikcyjnych) tekstów, konfrontacji „images” na przykład między sąsiadami, widać pewną niezależność od zewnętrznego (realnego) świata, a także odzwierciedlenie estetyki tożsamości i inności w konkretnej przestrzeni międzyliterackiej. Pojęcia imagologia wzbogaconego o określenie "porównawcza" po raz pierwszy użył w roku 1966 Hugo Dyserinck, jeden z twórców tej metody, który stworzył swój program w opozycji do strukturalistycznych koncepcji R. Welleka. Wellek odrzucił tę sferę badań jako przejściową modę w socjologicznej historii gustu artystycznego lub tak zwanej psychologii narodowej5.

Dyserinck całościowo pojmował imagologię jako metodę, która psychologizującą problematykę mentalności narodowych przekształca $\mathrm{w}$ pozbawione ideologicznego kontekstu przyglądanie się charakterowi narodowemu. Teorię Dyserincka w sposób zasadniczy dopełnił w latach osiemdziesiątych minionego wieku francuski komparatysta Daniel-Henri Pageaux 6 , który nawiązał do niektórych

E. Miner, Études comparées interculterelles, w: Théorie littéraire. Problèmes et perspectives. Red. T. M. Angenot, J. Bessière, J. D. Fokkema, E. Kushner. Paris 1999, s. 161-179.

3 Zob. C. Guillén, Mezi jednotou a růzností. Úvod do srovnávací literární vědy. Praha 2008 (w oryginale Entre lo uno y lo diverso. Introducción a la literatura comparada. Barcelona 1985).

${ }^{4} \mathrm{H}$. Dyserinck, Zum Problem der "images" und "mirages" und ihrer Untersuchung im Rahmen der Vergleichenden Literaturwissenschaft. "Arcadia“ 1996, nr 1, s. 107-120.

${ }^{5}$ Zob. Teorie medziliterárnosti 20. storočia I-II. Red. P. Koprda. Nitra 2009-2010. Antologię recenzowała A. Zelenková, Svetovna primerjalna književnost in njen slovanski prispevek. „Primerjalna književnost“ 2011, nr. 1, s. 266-271.

${ }^{6}$ Zob. D. H. Pageaux, Komparatistik. Eine Einführung. Bonn 1991, s. 125-133, 187-188; D. H. Pageaux, L'imagerie culturelle: de la littérature comparée à l'anthropologie culturelle. „Synthesis“ 1983, nr 10, s. 79-88. 
słowiańskich koncepcji: konkretnie do teorii recepcji Dýoniza Ďurišina i do komunikacyjnego modelu Jurija Łotmana. Lotman rozumie komunikację jako umiejętność znalezienia wspólnego języka na podstawie różnych kodów. Również Durišin mówi o tym, że literaturom pozostającym w bliskim kontakcie należy przyglądać się we wzajemnych relacjach $\mathrm{w}$ taki sposób, jakby były sobie obce, jakby realizowały się między nimi wyłącznie zależności typologiczne. W perspektywie imagologicznej tekstów nie dzielimy na podstawie ich wartości estetycznej, ale na podstawie istotności ich tematyki, a szczególnie zasięgu recepcyjnego oddziaływania na krąg odbiorców. Poza strefą zainteresowań, jako problem niedający się rozstrzygnąć, pozostaje kwestia "prawdziwości obcego", ponieważ obraz zawsze kogoś reprezentuje, zastępując coś lub kogoś, podczas gdy na pierwszym miejscu znajdują się idee, którym „obraz obcego" jest podporządkowany. Imagologia oferuje dzięki temu metodologiczny punkt wyjścia do pisania alternatywnej historii literatury z perspektywy obrazowości. O ile dla wcześniejszych badań była charakterystyczna pewna metodologiczna ekskluzywność, która umożliwiała odczytanie tekstu tylko w jeden sposób, o tyle imagologia domaga się prawa bricolage i nawarstwiania dróg metodologicznych, zaczynając od czysto estetycznej analizy na badaniach historycznych i kulturologicznych kończąc.

Właśnie ową imagologiczną perspektywę możemy wykorzystać przy badaniu wzajemnego „postrzegania się" Europy Środkowej i Rosji w ramach geografii symbolicznej i literackiej. Oczywistym wydaje się fakt, iż Europa Środkowa jako przestrzeń $\mathrm{w}$ ujęciu kulturowym i geograficznym, ale także jako swego rodzaju przecięcie dróg między niesłowiańskim Zachodem a słowiańskim Wschodem, zawsze odznaczała się zmienną pozycją niestabilnych centrów i peryferii, specyficznym przenikaniem się etnosów i kultur, religii oraz ideologii. Wynikające z bliskości terytorialnej stałe "dotykanie się" kultur prowadziło do zintensyfikowania komunikacji i wymiany dóbr kultury, ale także do kolizji oraz konfliktów tradycji artystycznych i poetyk, norm i konwencji. Pozycja Europy Środkowej między dwoma mocarstwami - Niemcami i Rosją - zasadniczo wpływała nie tylko na polityczną, ale także na estetyczną komunikację między Zachodem a Słowiańszczyzną, która często przebiegała za pośrednictwem mitów, czyli fikcyjnych i subiektywnych wyobrażeń interpretujących rzeczywistość. W ten sposób była na przykład postrzegana literatura zachodnioeuropejska, cechująca się hegemonistycznym charakterem, przejawiającym się $\mathrm{w}$ uniwersalnym i ponadczasowym wyobrażeniu wspólnoty, z którą muszą się pogodzić części „peryferyjne” ${ }^{7}$. Wzajemne przybliżanie się i oddalanie między Zachodem i Rosją było konsekwencją religijnej oscylacji i „rozdwojenia” Słowian (szczególnie zachodnich), którzy, jeśli chodzi o kwestie wyznaniowe i polityczne, zbliżali się bardziej do Zachodu, ale jednocześnie uświadamiali sobie genetyczne pokrewieństwo z Rosją.

${ }^{7}$ F. Sinopoli, Il mito della letteratura europea. Roma 1999. 
W dyskursie publicystycznym i politologicznym można wskazać na często pojawiające sie dwie modelowe koncepcje Europy Środkowej: maksymalistyczną i minimalistyczną ${ }^{8}$. Według koncepcji minimalistycznej przestrzeń ta uważana jest za ostatnią „wyspę" Zachodu ze względu na wspólne struktury historyczne i wartości kulturowe; środkowoeuropejskość staje się w tej optyce cywilizacyjnie elitarnym punktem widzenia, który pozwala spoglądać z pewną wyższością na nieco zacofane Bałkany i Rosję, czyli na południową i wschodnią cześć Europy. W koncepcji minimalistycznej występują binarne opozycje, o których mówi francuski filozof - dekonstrukcjonista Jacques Derrida (my x oni, nasze $x$ obce, cywilizacja $x$ barbarzyńcy), mit centrum i peryferii, granic i końca Europy, który utwierdza dychotomiczną wizję Europy Środkowej. W ten sposób pojmuje Europę Środkową także Milan Kundera, który w dyskusji prowadzonej w połowie lat osiemdziesiątych ze środkowoeuropejskimi intelektualistami-emigrantami (György Konrád, Czesław Miłosz, Václav Havel i inni) zdefiniował tę przestrzeń jako specyficzny region zajmowany przez małe narody, usytuowany między Niemcami a Rosją, kulturowo przynależący do Zachodu, politycznie zaś, od roku 1945, zaliczany do Wschodu ${ }^{9}$. W koncepcji maksymalistycznej Europa Środkowa jest pojmowana $\mathrm{w}$ kategoriach przeważnie aksjologicznych, a konstrukty geograficzne są $\mathrm{w}$ tej koncepcji produktem ubocznym, samo istnienie środka Europy jest tym samym zachwiane i podane $\mathrm{w}$ wątpliwość, podobnie jak niekiedy celowe dzielenie Europy na poszczególne części. Europa, a więc i jej cześć środkowa, jest profilowana jako zbiór idei, kształtujących się pod wpływem zmian historycznych, w większości przypadków związanych z tradycją łacińskiego chrześcijaństwa.

Stosunek do Rosji traktują jako kluczowy dla Europy Środkowej (ŚrodkowoWschodniej) także Marcel Cornis-Pope i John Neubauer, redaktorzy czterotomowej pracy History of the Literary Cultures of East-Central Europe: Junctures and Disjunctures in the 19th and 20th Centuries I-IV, ktora powstała $\mathrm{z}$ inicjatywy l'Association Internationale de Littérature Comparée (AILC) ${ }^{10}$. Chodzi w zasadzie o porównawczą historię literatur pisanych w językach europejskich. $Z$ chaosu terminologicznego i zalewu politycznych konotacji związanych z pojęciem Mitteleuropa (Friedrich Naumann), Europa Środkowa, Europa Wschodnia i Bałkany redaktorzy wybrali nowe, neutralne pojęcie Wschodnia Europa Środkowa, które jest zbliżone do szerszego, klasycznego pojęcia Europy Środkowej i obejmuje prze-

8 Zob. M. Zelenka, Střední Evropa v souvislostech literární a symbolické geografie. Nitra 2008.

9 M. Kundera, Únos Západu. „150 000 slov“ 1985, nr 10 (opublikowany po angielsku pod nazwą The Tragedy of Central Europe, 1984); dalej zob. Ch. Balabánová, Stredná Európa a stredoeurópsky geografický kultúrny priestor. S prihliadnutím na interpretácie Milana Kunderu, Györgya Konráda, Václava Havla, Czestawa Miłosza. w: Hrdina v stredoeurópskych a balkánskych literatúrach 19. a 20. storočia. Bratislava 2004, s. 9-19.

${ }^{10}$ History of the Literary Cultures of East-Central Europe: Junctures and Disjunctures in the 19th and 20th Centuries I-IV. Red. M. Cornis-Pope, J. Neubauer. Amsterdam - Philadelphia 2004-2010. 
strzeń od Bałkanów aż po Morze Śródziemne lub inaczej rzecz ujmując, przestrzeń od Czech aż po Mołdawię. W ten sposób pojęcie to różni się od polskiego rozumienia Europy Środkowo-Wschodniej jako terytorium między Morzem Śródziemnym i Bałtykiem, które postawione zostało w opozycji do euroazjatyckiej „barbarzyńskiej" Rosji. W tej porównawczej koncepcji, inspirowanej francuską szkołą Annales, dziełami Michela Foucaulta, hermeneutyką, szczególnie zaś poststrukturalnym pojmowaniem historii jako plastycznej narracji i wielowarstwowego tekstu w znaczeniu "żywego", synergicznego organizmu, dochodzi do rezygnacji z konwencjonalnej metody wykładu i kryteriów tradycyjnie wykorzystywanych do badań. Redaktorzy tej pracy z najróżniejszych punktów widzenia układają pluralistyczny i materialny dyskurs "mikrohistorii“. Z tego wynika przede wszystkim zainteresownie międzykulturowym dialogiem, fenomenem emigracji, cenzury, „uciśnionej” literatury, akcentowane są kategorie biliteralności, autorska wielojęzyczność i literatury miejszości, lub raczej sposób koegzystencji mikro- i makroliteratur $\mathrm{w}$ konkretnym regionie. $\mathrm{W}$ takim podejściu można dostrzec inspirację bachtinowską dialogicznością kultur, niektórymi koncepcjami postkolonialnymi obecnymi we współczesnej komparatystyce, jak np. pracami Homiego Bhabhy ${ }^{11}$ czy Armanda Gnisciego ${ }^{12}$. Redaktorzy w kontekście związków Europy Środkowej i Rosji podkreślają raczej przeciwstawność i binarność, nie poszukując punktów styczności. Marcel Cornis-Pope zwraca uwagę, że „sovietsky inšpirovaný pojem východnej Európy odpojil región od jeho tradičných interakcií so strednou a západnou Európou... aby odlišil región od východných a juhovýchodných imperiálnych mocností, cárskeho Ruska, Sovietskeho zväzu a Otomanskej ríše"13.

Czeski komparatysta Karel Krejčí w znakomitej pracy Mýtus a dialog v historických vztazích Slovanstva se Západem ${ }^{14}$ odrzucił teorię o braku kulturowej równowagi między Zachodem i Wschodem i ich nierównomiernym rozwoju. W przypadku związku Europy Środkowej i Rosji mówił o micie, który w procesie swojego "obiegu" stawał się faktem historycznym oddziałującym konstruktywnie, ale raczej w sposób destrukcyjny. $Z$ jednej strony językowo-etniczne pokrewieństwo oznaczało tu wysiłek prowadzący do tworzenia wspólnych zespołów lub jednolitych struktur, z drugiej strony możliwość państwotwórczego porozumienia i intensywnego kulturalnego zbliżenia podawała w wątpliwość podział terytorium zamieszkałego przez Słowian na liczne kulturalne i polityczne sfery. Między Europą Środkową i Rosją istnieje specyficzny rodzaj komunikacji polegającej na ciągłym procesie "przyciągania się" i "odpychania", który jest charakterystyczny

${ }^{11}$ H.K Bhabha, The Location of Culture. New York 1994.

12 A. Gnisci, Introduzione alla letteratura comparata. Milano 1999.

${ }^{13}$ M. Cornis-Pope, Písanie Dejín literárnych kultúr východo-strednej Európy: Retrospektíva. „World Literature Studies“ 2010, nr. 4, s. 42.

${ }^{14} \mathrm{~K}$. Krejčí, Mýtus a dialog v historických vztazích Slovanstva se Západem, w: Československé prednášky pro VI. mezinárodní sjezd slavistů v Praze. Praha 1968, s. 197-204. 
przede wszystkim dla Czechów i Polaków z grupy Słowian zachodnich. Do osiemnastego wieku w relacjach Środkowej Europy z Rosją odgrywały ważniejszą rolę kryteria związane z organizacją kościelną i samą religią, ale od czasów słowiańskiego odrodzenia narodowego rosło znaczenie kontaktów kulturalnych, wzajemnego poznawania się i konstruowania mitów narodowych rozprzestrzeniających się masowo niemal jako stereotypy narodowe. Podczas gdy rosyjska elita intelektualna znała Europę Środkową i Zachodnią dzięki swoim prywatnym kontaktom i podróżom śladami kultury, czytała $\mathrm{w}$ oryginale dzieła angielskich, niemieckich i francuskich klasyków, słowiańską Europę Środkową, z wyjątkiem Polski, ignorowała lub traktowała w sposób przedmiotowy. Według Krejčiego Zachód zaczął systematycznie odkrywać Rosję dopiero w osiemnastym wieku dzięki reformom Piotra Wielkiego. Krejčí w stosunkach Zachodu i Rosji identyfikował trzy mity, które pojawiły się w osiemnastym wieku i wpłynęły także na wzajemne "postrzeganie się": 1. Podziw francuskich encyklopedystów i Woltera dla carycy Katarzyny Wielkiej, jako władczyni oświeconej, wprowadzającej w warunkach absolutyzmu carskiego ustrój demokratyczny; 2. Stojący w opozycji do pierwszego mit francuskich przeciwników monarchii, idealizujących polską szlachtę jako reprezentanta „europejskich“ wartości w walkach przeciwko Rosji i 3. Najbardziej popularny mit o Słowianach rozszerzył niemiecki przedstawiciel odrodzenia Johann Gottfried Herder w dziele Ideen zur Philosophie der Geschichte der Menscheit, w którym podkreślał pokojową rolę Słowian i przypisał im przywódczą rolę w dziejach świata. Czeski komparatysta doszedł do wniosku, że rosyjsko-europejskie mity nawet pomimo swojego fikcyjnego charakteru „prokázaly tvořivou sílu, která... byla schopna vytvářet skutečnost “15.

W dziewiętnastym wieku stosunki Europy i Rosji rozwijały się na tle strategicznych refleksji na temat politycznej i kulturalnej orientacji $\mathrm{w}$ warunkach narodów środkowoeuropejskich, które według aktualnego zapotrzebowania podkreślały swoje podwójne, bądź zachodnioeuropejskie, bądź wschodnie (rosyjsko-bizantyjskie), korzenie. Koncepcja ta znalazła swoją teoretyczną wykładnię w pracach pruskiego militarysty Friedricha Naumanna w okresie pierwszej wojny światowej jako część niemieckiej wojennej propagandy starającej się stworzyć monarchię środkowoeuropejską podporządkowaną Niemcom ${ }^{16}$. Podczas gdy austroslawista František Palacký uważał utworzenie wielkich zespołów, opartych na zasadach federacji za element stabilizujący środkowoeuropejską kulturalną i polityczną równowagę i z czeskiego punku widzenia "mityczny środek” wiązał z Europą Zachodnią, odmienną opinię miał na ten temat słowacki działacz odrodzeniowy L'udovít Štúr, który w swojej po niemiecku napisanej pracy Das Slawenthum und die Welt der Zukunft (Slovanstvo a svet budúcnosti) doszedł do radykalnego wniosku:

\footnotetext{
${ }^{15}$ Ibidem., s. 201.

${ }^{16}$ F. Naumann, Mitteleuropa. Berlin 1915.
} 
środkowoeuropejskie, słowiańskie narody, jeśli chcą zachować wolność, muszą bardziej zbliżyć się do słowiańskiego Wschodu i stworzyć monarchistyczną unię $\mathrm{z}$ carską Rosją ${ }^{17}$. W przeciwieństwie do tego w polskim rozumieniu pojęcie Europy Środkowej w wyniku odmiennego kulturalnego i historycznego rozwoju terminologicznie zlewało się z innymi terminami jako Europa Środkowo-Wschodnia, lub Wschodnia (Oskar Halecki, Piotr Wandycz i inni), Euroazja, Międzymorze (region między Bałtykiem i Morzem Śródziemnym), co było wynikiem bezpośredniego geograficznego sąsiedztwa z Rosją, lub raczej Ukrainą, oraz z istnieniem Rzeczpospolitej. ${ }^{18} \mathrm{~W}$ polskim kontekście koncepcje Europy Środkowej były modyfikowane przez ideę średniowiecznego państwa polskiego, w którym obok dominujących Polaków żyli w pokojowej symbiozie i symbolicznej ochronie przed Rosją (rozumianą jako część „barbarzyńskiej” Azji) Ukraińcy, Białorusini i Litwini. Europa Środkowo-Wschodnia w polskiej tradycji oznacza również region między Niemcami i Rosją, który jest częścią Europy Zachodniej z kulturalnego punktu widzenia i stanowi opozycję w stosunku do wartości euroazjatyckiej Rosji, chodzi więc o przestrzeń Europy Środkowej, ale bardziej przesuniętą na Wschód.

Na Węgrzech, lub raczej w historycznych Dolnych Węgrzech ${ }^{19}$, idea Europy Środkowej cieszyła się stałą popularnością i często pojawiała się w literaturze pięknej i pracach naukowych: izolowana pozycja języka węgierskiego jako należącego do grupy ugrofińskiej, znajdującego się między słowiańsko-germańskimi grupami etnicznymi, skłaniała do intensywnego badania kulturowej wyjątkowości, a tym samym do uformowania i zrozumienia misji pośrednika w przestrzeni środkowoeuropejskiej. Pojawiała się tu szczególnie idea wielkich Węgier, obejmujących także terytorium dzisiejszej Słowacji. Węgierski stosunek do Rosji był $\mathrm{w}$ dziewiętnastym wieku wyznaczany $\mathrm{w}$ większym stopniu przez racjonalne niż emocjonalne czynniki, jak było w przypadku Czechów i Polaków: wiązało się to z pozycją narodu "tworzącego państwo" - stabilnej części monarchii habsburskiej, a także z językowo-etniczną izolacją. Węgierski publicysta żydowskiego pochodzenia Paul Lendvai metaforycznie porównał tamtejsze etnikum do „najbardziej osamotnionego narodu“ Europy a jego historię charakteryzował jako "tisíc let vítězství v porażkach" 20. Lendvai ma na myśli nie tylko wyjątkowość języka węgierskiego ze względu na jego przynależność do grupy ugrofińskiej, ale także specyficzny sposób, w jakim naród ten umiał pogodzić się z historycznymi katastrofami i przeciwnościami losu. Tu możemy szukać korzeni silnego przeświadczenia, że

17 Zob. A. Zelenková, Nevzájomnost’ v česko-slovenských vztahoch ako prook „vzájomnej inakosti“ (L'udovit Štúr a Samo Czambel), w: eadem, Medzi vzájomnostou a nevzájomnostou. Sondy do česko-slovenských a slovensko-českých literárnych vzt́ahov. Praha-Nitra 2009, s. 205-226.

${ }_{18}$ Zob. O. Halecki, Borderlands of Wetern Civilization. A History of East-Central Europe. New York 1952; P.S. Wandycz, Střední Evropa v dějinách od středověku do současnosti. Cena svobody. Praha 2002.

19 Obejmujących terytorium dzisiejszych Węgier i części Chorwacji (przyp. tłumacza).

${ }^{20}$ P. Lendvai, Tisíc let mad'arského národa. Praha 2002 (chodzi o podtytuł książki). 
rozpad Austro-Węgier oznaczał katastrofę dla politycznej historii Europy Środkowej oraz że konsekwencje tego „neseme ještě dnes” 21 to znaczy doszło do subiektywnie rozumianego rozbicia, a nie do dającego się oczekiwać naturalnego rozpadu monarchii habsburskiej.

Jest oczywiste, iż stosunek Środkowoeuropejczyków do Rosji poddawany był ciągłym aktualizacjom w egzystencjalnych, kluczowych momentach rozwoju i był ograniczany do kwestii wyborów historycznych i orientacji kulturalnej. Jeśli środkowoeuropejska refleksja na temat Rosji zawsze kształtowała się na tle bardziej intensywnej lub, przeciwnie, swobodniejszej przynależności do niesłowiańskiego Zachodu, w praktyce wyglądało to wręcz odwrotnie - wahała się pod wpływem orientacji politycznej i celów strategicznych: wpływała na to także lokalizacja geograficzna. Na przykład czeski stosunek do Rosji oznaczał stale obecną dyskusję o sensie czeskich dziejów, to znaczy o europejskich korzeniach kultury narodu czeskiego, a więc i jego miejscu w Europie. Trudno znaleźć znaczącego czeskiego historyka lub filozofa, który nie wypowiedziałby się w tej kwestii. $Z$ wielu wypowiedzi, spostrzeżeń, a także teorii, do których przykładowo możemy zaliczyć spór o Rukopis zelenohorský, wystąpienia Hugo Gordona Schauera, Tomaša Garrika Masaryka, historyczną spuściznę pozytywistycznej szkoły Jaroslava Golla i późniejszy dyskurs $\mathrm{w}$ dwudziestym wieku, jak przekonująco udokumentował czeski historyk Miloš Havelka w pracy Spor o smysl českých dějin 1895-1938 (1997), wyłoniła się główna idea. W antynomii Zachód-Wschód Czesi zawsze czuli się kulturalnie i politycznie związani z Europą Zachodnią, która geograficznie obejmowała na początku dziewiętnastego wieku rozbite niemieckie księstwa i dzisiejsze państwa Beneluxu22. W podobny sposób rozumiał także Europę Środkową T. G. Masaryk, który krytykował wyobrażenie Naumanna o dominującym niemieckim wpływie w Europie Środkowej. Masarykowi przeszkadzała idea prawnopaństwowego połączenia Rzeszy Niemieckiej z monarchią habsburską jako dwóch sojuszników w czasie wojny, jak również groźba germanizacji i asymilacji. Masaryk w swoim dziele Nová Evropa (1920) rozumiał Europę Środkową jako fikcyjny pas geograficzny sięgający z północy na południe, od Bałtyku po Morze Śródziemne. Region ten według niego odznacza się etniczną, językową i kulturową różnorodnością, tworzą go małe narody, które zamieszkują teren od Skandynawii aż po południową Grecję. Dlatego Masaryk do środokowoeuropejskich narodów zaliczał Szwedów, Norwegów, Duńczyków, Finów, Łotyszy, Estończyków i Litwinów, a także Polaków, Serbów Łużyckich, Słowaków, Węgrów, Słowińców, Serbów i Chorwatów, Rumunów, Albańczyków, Greków, Bułgarów, a częściowo nawet europejskich Turków, ale według niego nie należą do Europy Środkowej ani Niemcy, ani Austriacy, ani oczywiście Rosjanie.

\footnotetext{
${ }^{21}$ F. Fejtö, Rekviem za mrtvou říši. O zkáze Rakouska-Uherska. Praha 1998, s. 6.

22 J. Křen, Dvě století střední Evropy. Praha 2005.
} 
Niemiec do Środkowej Europy nie zaliczał także w swoich uwagach słowacki polityk i dyplomata Milan M. Hodža, który w napisanej po angielskiu pracy Federation in Central Europe (1944) odrzucił kulturalną i polityczną integrację Niemiec z Europą Środkową. Właśnie istnienie dwóch wielkich mocarstw - Niemiec i Rosji - jest rzeczywistym powodem powstania federacyjno-demokratycznej Europy Środkowej, która leży na granicy dwóch bloków cywilizacyjnych: Okcydentu i Orientu. W swojej koncepcji Hodža w zasadzie modyfikował koncepcję habsburskiej Europy Środkowej, pozbawiał ją jednak autorytetu monarchii. W tym punkcie projekt ten różni się od tego zaproponowanego przez czeskiego polityka Edwarda Beneša, w latach trzydziestych forsującego koncepcję Małej Ententy (Czechosłowacja, Rumunia i Jugosławia) jako jeden ze bloków zapewniających równowagę polityczną w Europie skierowany przeciwko formującemu się niemiecko-włoskiemu zagrożeniu. Hodža uświadomił sobie, że rozwój polityczny na początku dwudziestego wieku prowadzi do politycznej i gospodarczej integracji, do konstruowania wielkich całości, przeszkodą w tym procesie jest jednak mikroetatyzm, czyli polityczne i etniczne rozbicie Europy Środkowej. Dlatego tworzenie nowej mapy Europy musi być związane ze zmianą przestrzeni środkowoeuropejskiej, która nie powinna być jedynie pasmem przejściowym między mocarstwowymi interesami carskiej Rosji i Niemiec o cesarskich tradycjach. Hodža sympatyzował także z poglądami austriackiego polityka i założyciela ruchu paneuropejskiego Richarda Coudenhove'a-Kalergiego. Ten dał w roku 1923 impuls do założenia tzw. Międzynarodowej Unii Paneuropejskiej, której koncepcja zakładała polityczną integrację przemysłowo rozwiniętych państw zachodnioeuropejskich i środkowoeuropejskich z wyjątkiem Wielkiej Brytanii i Związku Radzieckiego. W odróżnieniu od Coudenhove'a-Kalergiego Hodža w swoim krytycznym stosunku do Rosji odrzucał jednak jej izolację i nie był przeciwnikiem handlowej współpracy z komunistami. Coudenhove-Kalergi odwrotnie - w swojej pracy PanEuropa (1923) konsekwentnie zwracał uwagę, że europeizacja Rosji od czasów Piotra Wielkiego przebiegła tylko formalne i że zarówno carskie, jak i bolszewickie zasady władzy były zawsze autorytatywne i stały w opozycji do tradycji europejskiej. Rosyjskiej inwazji na Zachód i przyłączeniu słowiańskich państw środkowoeuropejskich do imperium może zapobiec wyłącznie polityczna integracja małych środkowoeuropejskich narodów na zasadach federacji.

Podsumujmy: wzajemne postrzeganie się Europy Środkowej i Rosji rozwijało się na tle ogólnego związku między Zachodem i Wschodem. Najbardziej intensywnie w stosunku do Rosji określały się małe narody słowiańskie żyjące w monarchii habsburskiej. W tym samym czasie Rosja postrzegała te grupy etniczne w sposób utylitarny z perspektywy imperialnego "mocarstwa“ nie bacząc na etniczne pokrewieństwo (np. rok 1848 albo 1968). Rosyjskie zainteresowanie Europą było ukierunkowane raczej na Niemcy, Francję lub Anglię, a środkowoeuropejski region traktowano jako pasmo przechodnie, które służyło do przeforsowania mo- 
carstowowych interesów carskiej Rosji lub Związku Radzieckiego w kierunku Zachodu. W przeciwieństwie do tego środkowoeuropejskie, a więc i czeskie określanie się $\mathrm{w}$ stosunku do Rosji jako inspirującego punktu odniesienia i symbolu słowiańskiej niezależności, wzmacniało się w momentach kryzysu, zagrożenia i politycznej niepewności. Poglądy te łączyło przeświadczenie, że „nieeuropejska” Rosja, jej „inność” będzie się demokratyzować, dostosowywać do rodzimych tradycji i w ten sposób dojdzie do poparcia czeskich interesów w geopolitycznej konfrontacji z niesłowiańskim Zachodem ${ }^{23}$. W dobie stabilizacji i w czasie przyłączania państw Europy Środkowej do struktur zachodnich polityczne, gospodarcze i kulturalne stosunki Europy Środkowej i Rosji zmieniały się i osłabiały (np. okres po roku 1989 i rozpad Związku Radzieckiego). Także na początki XXI wieku stosunki między Rosją a Europą Środkową nie przestały być przedmiotem trwałego metakrytycznego dyskursu. Nie pozostaje nam nic innego niż mieć nadzieję, że relacje Europy Środkowej i Rosji pozostaną przykładem pełnego tolerancji współżycia i szacunku, przede wszystkim jednak przykładem spotykania się i wzajemnego zrozumienia.

${ }^{23}$ Zob. V. Doubek, Česká politika a Rusko (1848-1914). Praha 2004, s. 292-293. 




